\title{
Infrasellar Extension of Pituitary Macro-Adenomas
}

\author{
AHMED R. RIZK, M.D.**** and MARTIN BETTAG, M.D.* \\ The Department of Neurosurgery, Brueder Hospital Trier, Germany* and Banha Faulty of Medicine*,**, Egypt
}

\begin{abstract}
Background: Growth patterns of pituitary adenomas have been observed to vary according to the histopathological subtype.

Aim of Study: The authors aimed to analyse infrasellar extension pattern in cases of functional and non-functional macroadenomas.

Patients and Methods: Retrospective analysis of pituitary adenoma patients who underwent endoscopic trans-sphenoidal surgery in the time period between 2007 and 2013 at our institute. Patients with microadenomas and prior operations were excluded from the analysis. Preoperative MR images were reviewed to assess patterns of extrasellar extension in the varying tumor subtypes.

Results: The cohort comprised 150 patients, after exclusion of microadenomas and previously operated patients, the analysis involved 93 cases. Most of the cases were nonfunctional macroadenomas ( 66 patients, $71 \%$ ), the remaining were functional macroadenomas (GH-macroadenoma: 17 patients, 18\%; Macroprolactinoma: 8 patients, $9 \%$; TSHproducing macroadenoma: 1 patient, $1 \%$; and ACTH-cell macroadenoma: 1 patient, $1 \%$ ). Extension of the non-functional macroadenomas occurred into the following regions: Suprasellar, 63 patients (96\%); infrasellar, 11 patients (17\%); and parasellar, 17 patients (26\%). Extension of the GH-macroadenomas occurred into the following regions: Suprasellar, 7 patients (41\%); infrasellar, 9 patients (53\%); and parasellar, 3 patients (18\%). Extension of macroprolactinomas occurred into the following regions: Suprasellar, 8 patients $(100 \%)$; infrasellar, 2 patients $(25 \%)$; and parasellar, 4 patients $(50 \%)$. Isolated infrasellar extension was noticed in 8 patients with $\mathrm{GH}$-macroadenoma (47\%) and in 2 patients with non-functional macroadenoma (3\%). GH-macroadenomas had higher overall rates of infrasellar extension $(53 \%, p<0.05)$, and isolated infrasellar extension $(47 \%, p<0.05)$.
\end{abstract}

Conclusions: Extrasellar growth patterns in cases of pituitary macroadenoma showed substantial differences in relation to histological subtypes. GH-macroadenomas demonstrated a tendency for infrasellar extension. Existing data suggests lower surgical cure rates in adenomas with infrasellar extension. This fact may contribute particularly to the low normalisation rate after GH-adenoma surgery. If adaption of surgical technique may lead to better results, should be addressed in prospective studies.

Correspondence to: Dr. Ahmed R. Rizk, E-Mail: arizkrizk@gmail.com
Key Words: Infrasellar extension - Clival erosion - Acromegaly - GH-secreting adenoma.

\section{Introduction}

PITUITARY adenomas are the most commonly occurring neoplasms of the sellar region that typically become symptomatic due to mass effect on surrounding structures and/or hormonal oversecretion [1]. Invasion of the surrounding dura mater and extension into parasellar compartments occur in a significant proportion of these tumors and have been correlated with patient age, tumor size, and histopathological subtype [2-4]. The degree of resection, as well as the incidence of subsequent tumor recurrence, has also been reported to correlate, in part, with the degree of invasion into surrounding regions [5-7]. Cavernous sinus invasion is the most studied of these factors, however, it is important to recognize that other anatomical factors also determine the feasibility of gross total surgical resection including tumor size and suprasellar extension, as well as infrasellar growth. GHsecreting adenomas have more tendency for infrasellar or clival invasion than other pituitary adenomas [1]. Complete tumor removal is the mainstay to cure acromegaly in these cases. In addition to tumor size, parasellar and infrasellar tumor extension were documented as the MRI criteria that predict the cure rate after surgery for GH-secreting adenoma $[\mathbf{5 , 8 ]}$. The aim of this study is to evaluate different extrasellar extension patterns in pituitary macroadenomas, with special emphasis on infrasellar extension pattern and its implications on completeness of tumor removal, recurrence as well as cure rate in cases of $\mathrm{GH}$-secreting adenomas.

\section{Patients and Methods}

We performed a retrospective analysis of 93 patients presenting with pituitary adenoma who underwent surgical treatment between 2007 and 2013 at our department. Exclusion criteria included 
prior surgical or radiation treatment and cases of microadenoma. Data were collected through analysis of patients' reports; preoperative MR images were analysed to assess patterns of extrasellar tumor extensions, operation reports were also analysed to evaluate completeness of tumor removal and patterns of extension especially infrasellar extension with erosion through the clivus. Accordingly, extrasellar tumor extension was divided into suprasellar extension, parasellar extension with cavernous sinus invasion, and infrasellar extension with erosion through the clivus. It was also documented if any extrasellar tumor extension pattern was isolated or associated with other patterns of extension. Adenomas were divided into nonfunctional and functional adenomas according to the preoperative hormonal profile. Statistical analysis was performed correlating the functional type of the tumor and different tumor extension patterns (SPSS-17, Bivariate analysis). We performed a detailed analysis of cases of infrasellar extension evaluating the implications that infrasellar extension may have on tumor recurrence and cure rate in cases of functional adenoma. The criteria of cure in cases of GH-secreting adenoma were: Normalization of IGF-I values for age and sex, GH concentration after OGTT $<0,4$ g/land basal GH concentration $<2.5 \mathrm{~g} / \mathrm{l}$.

\section{Results}

The analysis included 93 patients (55 males and 38 females) operated upon for pituitary macroadenoma through endoscopic transnasal transsphenoidal surgery. The mean age was 58 years (range: 22-84). 66 patients had non-functional pituitary adenomas, while in 27 patients the adenoma was functional; Growth hormone (GH)secreting adenoma (17 patients), prolactinomas (8 patients), Adrenocorticotrophic hormone (ACTH)secreting adenoma (1 patient) and Thyroid stimulating hormone (TSH)-secreting adenoma (1 patient). The most common pattern of extrasellar tumor extension was the suprasellar pattern (79 patients, $85 \%$ ), while parasellar extension was evident in 25 patients (27\%), and infrasellar extension occurred in 23 patients (25\%). Table (1) shows the extension patterns in different functional tumor types. Extension of the non-functional macroadenomas occurred into the following regions: Suprasellar (63 patients, 96\%); infrasellar (11 patients, $17 \%$ ); and parasellar (17 patients, 26\%). Extension of the GH-macroadenomas occurred into the following regions: Suprasellar (7 patients, $41 \%$ ); infrasellar (9 patients, 53\%); and parasellar (3 patients, $18 \%$ ). Extension of prolactinomas oc- curred into the following regions: Suprasellar ( 8 patients, 100\%); infrasellar (2 patients, 25\%); and parasellar (4 patients, 50\%). Isolated infrasellar extension was noticed in 8 patients with $\mathrm{GH}$ secreting adenoma (47\%) and in 2 patients with non-functional macroadenoma (3\%). The most common pattern of extension in the non-functional adenoma is the suprasellar extension (96\%), however infrasellar extension was the most common pattern of extension in $\mathrm{GH}$-secreting adenoma (53\%) and all cases of prolactinomas showed suprasellar extension. MRI performed immediately postoperative have shown residual tumor in 36 patients ( $38 \%$ ), the rate of residual tumor was highest in tumors with parasellar extension (20 patients $80 \%$ ) as shown in Table (2). Within a mean follow-up duration of 28 months (range: 3-91), tumor recurrence occurred in 10 patients $(11 \%)$, however the rate of recurrence in tumors with parasellar extension was $20 \%$ and in tumors with infrasellar extension was 13\% (Table 2).

\section{Infrasellar extension:}

Tumors with infrasellar extension occurred in 23 patients in our series, 11 patients had non-functional adenoma, 9 patients had GH-secreting Adenoma, 2 patients had prolactinoma, and 1 patient had TSH-secreting adenoma. Isolated infrasellar extension (tumors with only infrasellar and infrasellar components) occurred only in 10 patients (8 patients had GH-secreting adenoma and 2 patients had non-functional adenoma). GH-macroadenomas had higher overall rates of infrasellar extension $(53 \%, p<0.05)$, and isolated infrasellar extension $(47 \%, p<0.05)$. Tumor recurrence was slightly higher in cases of infrasellar extension in comparison with the overall rate of recurrence in the whole series (13 vs $11 \%)$.

\section{GH-secreting adenoma:}

17 patients were treated for acromegaly resulting from $\mathrm{GH}$-secreting macroadenoma. Eight patients had tumors with isolated infrasellar extension, 5 patients had tumors with isolated suprasellar extension, 2 patient had tumor with isolated parasellar extension, however 2 tumors showed extension in more than one region. Residual tumor was evident in six of these patients, three patients had tumors with parasellar extension, two patients had tumors with infrasellar extension while the last patient had tumor with suprasellar extension. Tumor recurrence occurred in only one patient, this patient had a tumor with isolated infrasellar extension. Hormonal cure was possible in 10 cases out of 15 cases of GH-secreting adenoma (66\%), the cure rate in cases with infrasellar extension was $62.5 \%$ 
( 5 out of 8 patients), while the cure rate in cases without infrasellar extension was $71.4 \%$ (5 out of 7 patients).

Table (1): Extrasellar extension patterns in functional and non-functional pituitary adenomas.

\begin{tabular}{lcccc}
\hline $\begin{array}{l}\text { Tumor Type/ } \\
\text { Extension }\end{array}$ & $\begin{array}{c}\text { Supra- } \\
\text { sellar }\end{array}$ & $\begin{array}{c}\text { Parase- } \\
\text { llar }\end{array}$ & $\begin{array}{c}\text { Infrase- } \\
\text { llar }\end{array}$ & $\begin{array}{c}\text { Isolated } \\
\text { infrasellar }\end{array}$ \\
\hline Non-functional A & 62 & 17 & 11 & 2 \\
GH-secreting A & 7 & 3 & 9 & 8 \\
Prolactinoma & 8 & 4 & 2 & 0 \\
ACTH-secreting A & 1 & 0 & 0 & 0 \\
TSH-secreting A & 1 & 1 & 1 & 0 \\
\hline Total & 79 & 25 & 23 & 10 \\
\hline
\end{tabular}

Table (2): Residual tumor and recurrence.

\begin{tabular}{lcccc}
\hline & $\begin{array}{c}\text { All } \\
\text { Tumors }\end{array}$ & $\begin{array}{c}\text { Infrasellar } \\
\text { extension }\end{array}$ & $\begin{array}{c}\text { Parasellar } \\
\text { extension }\end{array}$ & $\begin{array}{c}\text { Suprasellar } \\
\text { extension }\end{array}$ \\
\hline $\begin{array}{c}\text { Residual } \\
\text { tumor }\end{array}$ & $36(38 \%)$ & $12(52 \%)$ & $20(80 \%)$ & $30(38 \%)$ \\
Recurrence & $10(11 \%)$ & $3(13 \%)$ & $5(20 \%)$ & $9(11 \%)$ \\
\hline
\end{tabular}

\section{Discussion}

Extrasellar extension of pituitary adenoma poses sometimes limitation for complete tumor resection and may result in residual tumor that may cause disease progression especially in functional adenomas. Therefore, thorough evaluation of preoperative MR images to define the pattern of extrasellar extension is of paramount importance prior to attempting surgery for these tumors [1]

It was reported that the degree of invasion of pituitary adenomas into the surrounding regions has an effect on the degree of resection and subsequently on the incidence of tumor recurrence [5-7]

Zada et al., compared the patterns of extrasellar extension between the non-functional adenomas and the GH-secreting adenomas. The authors found that suprasellar extension was more common in non-functional adenomas ( $82 \%$ vs. $16 \%$ ), infrasellar extension was more common in $\mathrm{GH}$-secreting adenomas ( $72 \%$ vs. $46 \%$ ), while parasellar extension was slightly more common in non-functional adenomas (40\% vs. $16 \%)$. In addition, isolated infrasellar extension was found to be significantly higher in GH-secreting adenoma (52\% vs. $6 \%$, $p<0.0001)$ [1] .

Other studies reported that GH-secreting adenomas frequently noted to invade the sphenoid sinus and clivus $[\mathbf{1 0 , 1 1}]$.

The results of our study have shown that nonfunctional adenomas extend most frequently in the suprasellar region ( $96 \%$ of the cases), however GH-secreting adenomas extend mostly infrasellar and through the clivus (53\% of the cases). Additionally, isolated infrasellar extension occurred in $47 \%$ of cases of GH-secreting adenomas. GHsecreting adenomas had higher overall rates of infrasellar extension $(p<0.05)$, and isolated infrasellar extension $(p<0.05)$.

The different biological nature of these tumors results in differentiation in their behaviour when they expand especially with invasion of the surrounding dura or bony structures. Studies have shown that the biology of GH-secreting adenomas may enable them to more easily invade surrounding dural and/or bony structures, perhaps due to differential expression of proteins involved with degradation, such as matrix metalloproteinases [12-14].

There are other explanations to the finding that $\mathrm{GH}$-secreting adenomas extend into the sphenoid sinus and into the clivus. One explanation is related to the anatomical topographic distribution of somatotrophs in the caudal and lateral part of the pituitary gland, therefore $\mathrm{GH}$-secreting microadenomas often arise in this location [1]. Other explanation is that GH causes thickening of the diaphragma sellae and the tumor causes enlargement of the sellar space, thus making the sellar floor thinner and more prone to tumor penetration [10]

One study has documented that $42 \%$ of the cases of GH-macroadenomas with isolated infrasellar extension, met WHO criteria for atypical adenomas [1]. On the contrary non-functional macroadenomas expand through the diaphragma sellae into the suprasellar compartment without primarily invading bony structures or the cavernous sinus, while atypical non-functional adenomas often invade multiple surrounding compartments [2-4].

Identification of residual tumor after surgery is of paramount importance especially in cases of functional adenomas as this usually require adjuvant treatment to achieve hormonal control. Tumors with parasellar extension as well as tumors with infrasellar extension are associated with higher rates of residual tumor in our series $80 \%$ and $52 \%$ respectively). As regarding $\mathrm{GH}$-secreting adenoma, complete tumor removal is mandatory to achieve normalization of IGF-1 after tumor removal. Identification of clival infiltration in these tumors is very important in order to achieve complete tumor removal. In our series the cure rate in cases of GHsecreting adeonoma with infrasellar extension was lower than cases without infrasellar extension $(62.5 \%$ vs $71.4 \%)$. 
Conclusions: Extrasellar growth patterns in cases of pituitary macroadenoma showed substantial differences in relation to histological subtypes. GH-macroadenomas demonstrated a tendency for infrasellar extension. Existing data suggests lower surgical cure rates in adenomas with infrasellar extension. This fact may contribute particularly to the low normalisation rate after $\mathrm{GH}$-adenoma surgery. If adaption of surgical technique may lead to better results, should be addressed in prospective studies.

\section{References}

1- ZADA G., LIN N. and LAWS E.R. Jr.: Patterns of extrasellar extension in growth hormone-secreting and nonfunctional pituitary macroadenomas. Neurosurg Focus 29 (4): E4, 2010.

2- LUNDIN P., NYMAN R., BURMAN P., LUNDBERG P.O. and MUHR C.: MRI of pituitary macroadenomas with reference to hormonal activity. Neuroradiology, 34 : 43-51, 1992.

3- MEIJ B.P., LOPES M.B., ELLEGALA D.B., ALDEN T.D. and LAWS E.R. Jr: The long-term significance of microscopic dural invasion in 354 patients with pituitary adenomas treated with transsphenoidal surgery. J. Neurosurg., 96: 195-208, 2002.

4- SELMAN W.R., LAWS E.R. Jr, SCHEITHAUER B.W. and CARPENTER S.M.: The occurrence of dural invasion in pituitary adenomas. J. Neurosurg., 64: 402-407, 1986.

5- BOURDELOT A., COSTE J., HAZEBROUCQ V., GAILLARD S., CAZABAT L., BERTAGNA X., et al.: Clinical, hormonal and magnetic resonance imaging (MRI) predictors of transsphenoidal surgery outcome in acromegaly. Eur. J. Endocrinol., 150: 763 771, 2004.

6- CHANG E.F., ZADA G., KIM S., LAMBORN K.R., QUINONES-HINOJOSA A., TYRRELL J.B., et al.: Longterm recurrence and mortality after surgery and adjuvant radiotherapy for nonfunctional pituitary adenomas. J. Neurosurg., 108: 736-745, 2008.
7- ZADA G., KELLY D.F., COHAN P., WANG C. and SWERDLOFF R.: Endonasal transsphenoidal approach for pituitary adenomas and other sellar lesions: an assessment of efficacy, safety, and patient impressions. J. Neurosurg., 98: 350-358, 2003.

8- VAN BUNDEREN C.C., VAN VARSSEVELD N.C., BAAYEN J.C., VAN FURTH W.R., ALIAGA E.S., HAZEWINKEL M.J., et al.: Predictors of endoscopic transsphenoidal surgery outcome in acromegaly: Patient and tumor characteristics evaluated by magnetic resonance imaging. Pituitary, 16 (2): 158-67, 2013.

9- GIUSTINA A., CHANSON P., BRONSTEIN M.D., KLIBANSKI A., LAMBERTS S., CASANUEVA F.F., et al.: A consenus on criteria for cure of acromegaly. J. of Clinical Endocrinology and Metabolism, 95 (7): 3141 3148, 2011.

10- HAGIWARA A., INOUE Y., WAKASA K., HABA T., TASHIRO T. and MIYAMOTO T.: Comparison of growth hormone-producing and nongrowth hormone-producing pituitary adenomas: Imaging characteristics and pathologic correlation. Radiology, 228: 533-538, 2003.

11- MARRO B., ZOUAOUI A., SAHEL M., CROZAT N., GERBER S., SOUROUR N., et al.: MRI of pituitary adenomas in acromegaly. Neuroradiology, 39: 394-399, 1997.

12- GONG J., ZHAO Y., ABDEL-FATTAH R., AMOS S., XIAO A., LOPES M.B., et al.: Matrix metalloproteinase9 , a potential biological marker in invasive pituitary adenomas. Pituitary, 11: 37-48, 2008.

13- HUSSAINI I.M., TROTTER C., ZHAO Y., ABDELFATTAH R., AMOS S., XIAO A., et al.: Matrix metalloproteinase- 9 is differentially expressed in nonfunctioning invasive and noninvasive pituitary adenomas and increases invasion in human pituitary adenoma cell line. Am. J. Pathol., 170: 356-365, 2007.

14- PÁEZ PEREDA M., LEDDA M.F., GOLDBERG V., CHERVÍN A., CARRIZO G., MOLINA H., et al.: High levels of matrix metalloproteinases regulate proliferation and hormone secretion in pituitary cells. J. Clin. Endocrinol. Metab., 85: 263-269, 2000. 


\title{
نهو أورام الغدة النخامية إلى أسفل السرج التركى
}

\author{
الخلفية العلمية: تختلف أنماط نمو أورام الفدة النخامية تبعاً لنوع الورم.
} الهدف من الدراسة: تهدف الدراسة تحليل نمو أودام الغدة النظامية الوظيفية وغير الوظيفية إلى أسفل السرج التركى.

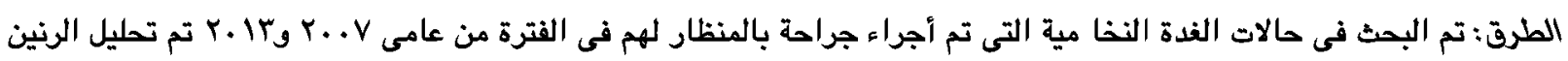

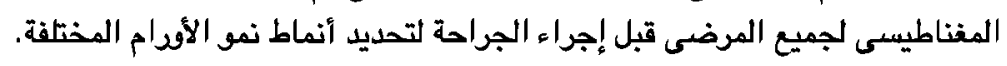

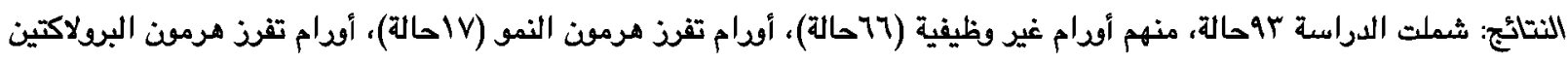

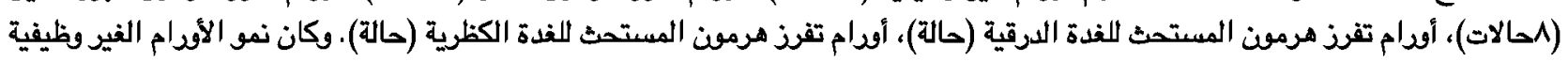

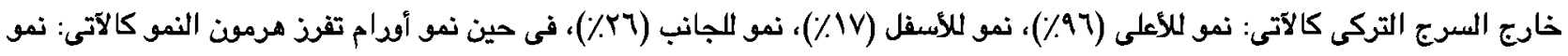

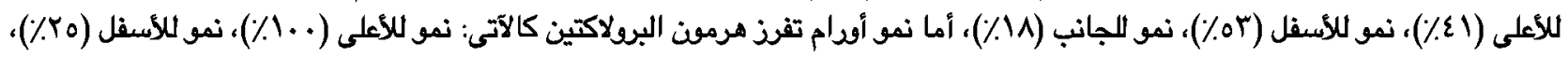
نمو للجانب (\%). (\%). (1\%).

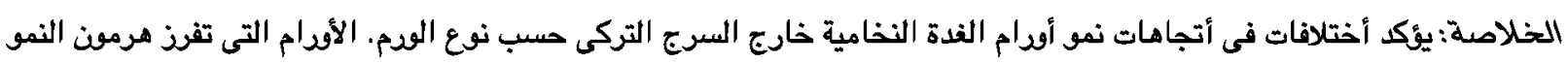

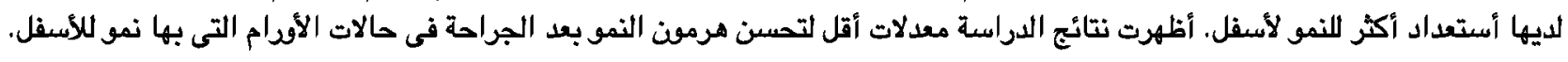

